\title{
PEDRO DE NAVARRA: REVISIÓN DE UN HUMANISTA. BIBLIOGRAFÍA REPERTORIADA DEL SIGLO XVIII
}

\author{
Gregorio Cabello Porras \\ Universidad de Almería
}

Tras la fundamental, pero confusa, aportación a la historiografía literaria en torno a Pedro de Navarra, que realizara Nicolás Antonio ${ }^{1}$, nos adentramos en un siglo en el que muchas de las indicaciones y acercamientos ya descritos tenderán a repetirse por inercia, pero que, sin embargo, va a proporcionarnos los primeros acercamientos certeros no sólo a la figura del autor sino al esclarecimiento de la confusión reinante sobre su corpus, no sólo en lo que abarca a sus diálogos y sus distintas ediciones, sino a su obra como cronista, y lo que más puede sorprendernos como novedad, su

\footnotetext{
${ }^{1}$ Recibido: 2/X/2009 Aceptado: 18/XI/2009

Finalizada en 1672, la primera edición de la Bibliotheca hispana nova tuvo lugar en Roma en 1696. Cito aquí por la edición de Madrid, Joaquín de Ibarra, 1783 en dos tomos. Manejo para ello la reprod. facsimilar de Madrid, Visor Libros, 1996. Contamos ya con la versión traducida, Biblioteca hispana nueva, o de los escritores españoles que brillaron desde el año MD hasta el de MDCLXXXIV, I-II, Madrid, Fundación Universitaria Española, 1999. En concreto me refiero a las entradas «D. PETRUS DE NAVARRA, alias DE LABRIT» y a la de «PETRUS NAVARRO», pp. 220-221.
} 
epistalorio, que aclarará muchas de las cuestiones que quedaron planteadas en un trabajo anterior ${ }^{2}$.

Seguiremos aquí el mismo proceder que en el trabajo mencionado, es decir, un examen de la bibliografía por orden cronológico.

\section{F. DE ALESON (1715)}

En F. DE AlESON, prmera aportación que debe ser reseñada por lo que comporta su doble función de esclarecimiento de las confusiones sembradas por la bibliografía del siglo XVII y por la perfilación biográfica bastante certera y cercana a la figura de Pedro de Navarra, leemos ${ }^{3}$ :

Fuera de estos le dâ Arnaldo Oihenart al Rey Don Juan un hijo natural avido antes de su matrimonio, que por aver sido hombre de gran provecho merece bien que le pongamos aqui. Este fue Pedro de Labrit, obispo de Convenas: el qual el año de 1561 fue por Embaxador à Roma al Papa Pio Quarto de parte de los principes de Bearne Antonio de Borbon, y Doña Juana de Navarra. Hallôse tambien en el Concilio de Trento. De èl refiere Fray Antonio de Yepes, que primero fue Monge Professo en el Monasterio de Yrache, y que alli se llamô Veremundo, y le alaba de muy singular ingenio. ${ }^{4}$

Aquí se comienzan a deslindar las que van a ser las grandes líneas en los estudios sobre Pedro de Navarra hasta bien entrado el siglo xx.

En primer lugar, las obras de A. de Yepes ${ }^{5}$ y A. d'Oihénart ${ }^{6}$ se toman como puntos de referencia para repetir, sin contrastar lo que en ellas se afirma, sus afirmaciones o anotaciones nucleares. En el caso concreto que nos ocupa, el de F. de Aleson, podemos comprobar cómo el «ingenio peregrino y raro» de Yepes da paso al «muy singular ingenio», sin mayores precisiones que puedan ir concretadas con referencias directas

2 Cf. G. Cabello Porras, «Pedro de Navarra: revisión de un humanista. Bibliografía repertoriada de los siglos XVI-XVII», Lectura y Signo, 3 (2008), pp. 65-115.

3 F. de Aleson, Annales del Reyno de Navarra, Tomo V o Segundo de su segunda parte, Viana (Navarra), F. Picart, 1715. Cito por J. de Moret y F. de Aleson, Annales del reyno de Navarra, reprod. facs. de la ed. de Pamplona, Pascual Ibañez, 1766, I-VI, presentación de J. M. Martín de Retama; epílogo de J. R. Castro Álava, Bilbao, La Gran Enciclopedia Vasca, 1969.

4 Ibidem, p. 1486.

5 A. de Yepes, Corónica General de la Orden de San Benito, Patriarca de Religiosos. Por el maestro Fray Antonio de Yepes. Tomo III. Centuria III, Irache, Nicolás de Assiayn, 1610, f. 378v.

6 A. d'Oihénart, Notitia utriusque Vasconiae tum Ibericae, tum Aquitanicae, qua praeter situm regionis et alia scitu digna, Navarre Regum, Gasconiae Principum, caeterarumque, iniis, insignium vetustae... (1637). Cito por la reprod. facsímil de la 2. ${ }^{a}$ edición de París, 1656, con estudio preliminar de R. Cierbide, y trad. del texto latino, J. Gorosterratzu, Vitoria-Gasteiz, Eusko Legebiltzarra-Parlamento Vasco, 1992, lib. III, cap. XII, p. 476 . 
a su obra impresa. ${ }^{7}$ De esta forma se comienza a reiterar de forma tópica uno de los rasgos que definirían a Pedro de Navarra, el de su elevada condición intelectual, aun cuando se desconozca su obra, ya sea en su totalidad o, lo que es más común, en forma parcial y fragmentaria, como ocurría en el caso de A. d'Oihénart. Así, F. de Aleson puede calificar a Pedro de Navarra como «hombre de gran provecho» ${ }^{8}$, atendiendo con ello, desde la perspectiva en la que se imbrica la obra de Aleson, a sus trabajos en pro de la causa navarra, diluyendo su humanismo en la praxis de una acción política concreta9.

A partir de Aleson asistiremos a un proceso en el que se atenuará considerablemente el retrato de Pedro de Navarra como alguien que en su momento perteneció a una orden religiosa, fraile benedictino caracterizado por una profunda religiosidad. Esto, que como era de esperar se acentuaba en la crónica de la orden escrita por Yepes, va a ir desapareciendo gradualmente de las semblanzas del humanista, a la vez que se incrementará su dimensión de hombre público, sujeto a unas determinadas circunstancias políticas y personales, que marcarán profundamente sus avatares vivenciales ${ }^{10}$.

A esto debemos añadir cómo la bibliografía de origen hispánico que aborda su figura va a distanciarse radicalmente de la que se escribe en Francia. Desde la vertiente española, tenderá a obviarse uno de los factores que veíamos como más determinantes en la semblanza de A. Galland ${ }^{11}$ : el de haber sido ferviente defensor de la causa de los reyes de Navarra, con todas las implicaciones de heterodoxia religiosa que ello conllevaba, dada la prelatura que ejercían entre los reformistas franceses

\footnotetext{
7 «Singular» en una de las acepciones del Diccionario de Autoridades:: «Por extensión vale extraordinario, raro, ù excelente», lo que nos remite a las acepciones ya revisadas de "peregrino». Cf. G. Cabello, loc. cit., p. 96, y «El motivo de la peregrintaio en Soto de Rojas: sumarización ejemplar de un itinerario en la vida y en la literatura», Barroco y Cancionero. El «Desengaño de amor en rimas» de Pedro Soto de Rojas, Málaga, Universidad de Málaga / Universidad de Almería, 2004, pp. 424-433.
}

8 Cf., por sus implicaciones, M. López Suárez, «El príncipe: la estrategia del líder», introd. a su ed. de N. Macchiavelli, El príncipe, Barcelona, Temas de Hoy, 1999. En la vertiente barroca, de la que Pedro de Navarra no deja de ser un precursor relevante, nos acercaría, en tanto que «ideal», al B. Gracián de $E l$ arte de la prudencia / Oráculo manual, ed. J. I. Díez Fernández, Barcelona, Temas de Hoy, 1993.

9 No es ajena esta tendencia al espíritu que alumbra el nuevo siglo, trazado con precisión desde ámbitos distintos por M. Baxandall, Las sombras y el Siglo de las Luces,, Madrid, Visor, 1997, desde una perspectiva in fieri, y P. Benichou, La coronación del escritor. 1750-1830. Ensayo sobre el advenimiento de un poder espiritual laico en la Francia moderna, México, Fondo de Cultura Económica, 1981, sin olvidar los fundamentos que sustentan las aportaciones de R. Assunto, Naturaleza y razón en la estética del setecientos, Madrid, Visor, 1989 y La Antigüedad como futuro. Estudio sobre la estética del neoclasicismo europeo, Madrid, Visor, 1990.

10 A. Galland, Mémoires pour l'histoire de la Navarre et de Flandre, contenants le droit du roy au royaume de Navarre..., París, Mathieu Guillemot, 1618, pp. 80-105.

11 Remito a la nota 13 del trabajo que precede a éste, en el que doy cuenta por extenso, de la bibliografía que concierne a lo que aquí se plantea. 
pertenecientes a las sectas luterana, calvinista o entre los hugonotes, tanto Antonio de Vendôme como Juana de Albret. Desde la vertiente francesa, se acentuará en cambio todo lo referido al interés personal y al afán de medro por parte de Pedro de Navarra, que no dudará, posiblemente teniendo en mente como objetivo último la restitución de la independencia o de cierta autonomía del reino de Navarra en su persona, como legítimo heredero, en ponerse al servicio indistintamente de los monarcas españoles o de los franceses, sin olvidar su precavida y cuidadosa relación con el papado. No sorprende la imagen que difundirán los historiadores franceses de un Pedro de Navarra poseedor de todos los rasgos que pueden caracterizar a un espía al servicio simultáneo de enemigos encontrados, imagen que su epistolario no ayuda a desmentir ${ }^{12}$.

\section{O. RAYNALDI (1727)}

O. Raynaldi ${ }^{13}$ retoma lo avanzado en A. de Yepes, Galland, A. d'Oihénart y Aleson, para dar cuenta del origen bastardo de Pedro de Navarra como hijo natural de Juan de Navarra, y de su condición de monje benedictino hasta su posterior toma de posesión del obispado de Cominges:

Petrus Albretius, Joannis Navarrae Regis filius naturalis, olim Benedictina: [Arnal. Oihenato in notit. Utriusq. Vasc.] familiae secundum Yepes alumnus, qui postea Convenarum Episcopus fuit. ${ }^{14}$

A continuación nos informa de los mismos acontecimientos que nos relataba A. Galland sobre la estancia de Pedro de Navarra en Roma, su petición de un consistorio público a Pío IV y el éxito que obtuvo cuando éste se celebró en diciembre de 1560.

Hic postridie idus Decembris à Pontifice ad colloquium publicè est admissus, quo tempore ejus nomine orationem ad Pontificem habuit Vir Clarissimus Marcus Antonius Muretus, ubi inter alia, quae de Pontifice est locutus, de Concilii ab ipso indictione facta haec subdit [...] Obsequio hujusmodi per Petrum exhibito Pius hisce verbis per Pontificium feribam respondere mandavit. ${ }^{15}$

12 O. Raynaldi, Annales ecclesiastici, XXI, 1: Ab anno MDXXXIV, Pauli III usque ad annum MDLXV Maximiliani II, Colonia, Ioannem Wilhelmum Friessem, 1727.

13 Ibid., pp. 255-256, n. 85.

14 Ibid., p. 256.

15 M. Baxandall, Giotto y los oradores. La visión de la pintura en los humanistas italianos y el descubrimiento de la composición pictórica 1350-1450, Madrid, Visor, 1996, p. 21. Cf., los apuntamientos, que desbordan el límite de lo acotado en su titulación, de J. Lara Garrido, «Andalucía y la oratoria», en E. Orozco Díaz, La literatura en Andalucía (de Nebrija a Ganivet), Málaga, Anejo LIx de Analecta Malacitana, 2006, pp. 197205,. Cf., para aspectos particulares de la oratoria sacra, posiblemente muy lejanos al acaecer de Pedro de Navarra, pero no a sus diálogos, la introducción de A. García Megía y M. a Dolores Mira y Gómez de Mercado, «Introducción» a Juan Falconi, Antología de textos, Almería, Universidad de Almería, 2009, y 
Una vez más se resalta la condición de orador de Pedro de Navarra como uno de los rasgos que van a caracterizar su faceta de «humanista». Y esto debe entenderse en el sentido que expone M. Baxandall:

Que los humanistas se llamaran a sí mismos oradores no quería decir que ejercieran todas las funciones retóricas de Cicerón, ni siquiera de Libanio (cosa que, por otra parte, les hubiera resultado imposible). La retórica de los griegos y de los romanos tenía dos caras. Por un lado, era un arte práctico de persuasión, orientado a la eficacia ante los tribunales y asambleas políticas; por otro, tenía un aspecto sofístico y pedagógico que permitía un empleo más libre de las técnicas y recursos retóricos, buscando más la corrección y el virtuosismo que la persuasión en sí. Pero, a pesar de que los aspectos educativo y práctico de la retórica clásica a menudo mantuvieron relaciones difíciles entre sí, la situación ideal en ambos casos seguía siendo la de un hombre en pie frente a un público ante el que poder exponer sus argumentos. ${ }^{16}$

Así, estas características que precisa M. Baxandall pueden ser aplicables a un Pedro de Navarra que orientó sus conocimientos de retórica y oratoria hacia el arte práctico de la persuasión, eficaz ante los tribunales o asambleas, en su caso los consistorios y su participación posterior en el Concilio de Trento. En definitiva, «la de un hombre en pie frente a un público ante el que poder exponer sus argumentos», público que en este caso se concreta en la figura de Pío IV, al que al final convence y persuade de que su causa, la reivindicación del reino de Navarra para sus soberanos legítimos, es la justa, ${ }^{17}$ con todo lo que ello podría implicar en el inestable equilibrio establecido entre las potencias europeas a mediados del siglo $\mathrm{XVI}^{18}$.

M. López Muñoz, Fray Luis de Granada y la retórica, Almería, Universidad de Almería, 2000.

16 Sería interesante para un trabajo posterior examinar el tipo de argumentación existente en el discurso de Mureto que leyó Pedro de Navarra (M. Antonii Muret, Opera omnia, I, édit. Runkenius, Lugduni Batavorum, 1789, pp. 51-59) para intentar analizar los recursos retóricos y ver si éstos están más incardinados en el arte de la predicación de las retóricas medievales o en un discurso persuasivo que hubiera asimilado las aportaciones de la Retórica a Herenio seudociceroniana (ed. S. Núñez, Madrid, Gredos, 1997). Vid. J. J. Murphy, La retórica en la Edad Media. Historia de la teoría de la retórica desde San Agustín hasta el Renacimiento, México, Fondo de Cultura Económica, 1986, cap. VI: «Ars praedicandi: El arte de la predicación» (pp. 275-362) y el apéndice «Figuras de dicción y de pensamiento de la Rhetorica ad Herennium, Libro IV» (pp. 371-380).

${ }_{17}$ Remito de nuevo a la exhaustiva nota a pie de página 13 del artículo previo a este trabajo donde se documenta ampliamente lo que aquí se indica.

18 C. de Vic y J. Vaissete, Histoire générale de Languedoc..., I-XIV, París, 1730-1745. Manejo la reedición de París, Claude Tchou (Bibliothêque des Introuvables), 2006. 
En el tomo IV de la Histoire générale de Languedoc, a cargo de Dom Claude Devic y Dom Joseph Vaissete ${ }^{20}$, se aporta un dato, inédito hasta entonces: el de que Pedro de Navarra hubiera compuesto una obra dedicada al cardenal Jorge de Armagnac con el título de Diálogos de los grados de perfección que ha de tener el cortesano eclesiástico que pretende ser cardenal, conservado en la Biblioteca Nacional de París. Surge así una faceta en la que debería abrirse un momento para la reflexión, desde una perspectiva crítica que busque integrar todas las contradicciones que van acumulándose sobre el perfil y los trazos con los que van forjándose la figura de Pedro de Navarra.

En ese afán de aunar su condición de hombre público y su faceta de humanista reflexivo sobre cuestiones que atañen en la mayor parte a la salvación espiritual del hombre, plantea aquí, ya desde el mismo título, lo que irónicamente podría considerarse todo un oxímoron: la figura del «cortesano eclesiástico» ${ }^{21}$ y la de la elaboración de una guía, conforme con esos presupuestos, para que aquél que se lo proponga pueda ascender en la jerarquía eclesiástica, acomodándose a una preceptiva rígida, en la que jerarquía estamental y moral cristiana difuminan sus deslindes ${ }^{22}$. Ya he hecho notar,

19 Histoire générale de Languedoc..., IV, París, 1730-1745, p. 377.

${ }^{20}$ No extraña o ajena para aquéllos que hayan transitado por las páginas de A. Chastel, Arte y humanismo en Florencia en la época de Lorenzo el Magnifico, Madrid, Castalia, 1982, o por las de F. Antal, El mundo florentino y su ambiente social, Madrid, Alianza, 1989, que tienen su continuidad en los estudios que se recogen en el volumen La Espada y la Pluma. Il mondo militare nella Lombardia spagnola cinquecentesca. Atti del Convegno Internazionale di Pavia, Viareggio - Lucca, Maroni, 2000, en la «España italiana» que describen M. López Suárez, «Introducción, Francisco de Figueroa, Poesía, Madrid, Cátedra, 1989, pp. 22-30 o C. Perugini, «Introducción», Francisco Delicado, La Lozana andaluza, Secilla, Fundación José Manuel Lara, 2004, que remiten como ejemplos a los estudios imprescindibles de B. Croce, La Spagna nella vita italiana durante la Rinascenza, Bari, Gius, Laterza \& Figli, 1968; a los ensayos recogidos en el volumen Italia e Spagna. Saggi sui rapporti storici, filofici ed artistici tra le due civiltà, Florencia, Felice Le Monnier, 1941 (esp. el ensayo de R. Quazza, «Spagna e Italia dal 1555 al 1631», pp. 163-192), todo ello amaparado por la labor de J. Siracusa y J. L. Laurenti, Relaciones literarias entre España e Italia. Ensayo de una bibliografía de literatura comparada, Boston: Mass., G. K. Hall, 1972, obras a las que se ha debido recurrir necesariamente en G. Cabello Porras, «Las Varias poesías de Hernando de Acuña: de un diseño estructural "renacentista" a una impresión "manierista"», Analecta Malacitana, XXX, 2 (2007), pp. 395-434, «Las Varias poesías (1591) de Hernando de Acuña: de Garcilaso a Boscán. El tránsito del humanismo militar a la "nueva lengua poética"», Dicenda. Cuadernos de Filología Hispánica, 26, 9-10 (2008), pp. 5-61 y el proyecto editorial de G. Cabello Porras y S. Pérez-Abadín Barro, Hernando de Acuña: de los versos de un renacimiento temprano y un humanismo militar a la prefiguración de un neoestoicismo y desengaño barrocos, que contará con colaboraciones de J. Lara Garrido. A. Gargano, A. Alonso, J. I. Díez Fernández, A. Río Torres-Murciano, A. Ruiz-Pérez, J. Matas Cabballero, M. Rubio Árquez, a más de colaboraciones individualidades de los editores.

${ }^{21}$ Los estudios que atañen a esta colisión entre jerarquía estamental eclesiática y verdad espiritual interior arrancan necesiariamente de M. Menéndez Pelayo, Historia de los heterodoxos españoles [1880], I-II, Madrid, Biblioteca de Autores Cristianos, $1987^{4}$; pasan por el filtro de M. Bataillon, Erasmo y España.Estudios sobre la historia espiritual del siglo XVI, México, Fondo de Cultura Económica, 1966², y encuentran su reinterpretación ajustada, con todas las precisiones perfectamente mesuradas, en el estudio de A. Rallo Gruss, Erasmo y la prosa renacentista españolala, Madrid, Laberinto, 2003.

22 G. Cabello Porras, «NAVARRA, Pedro DE», en el proyecto, coordinado por P. Jauralde, del Diccionario Filológico de la Literatura Española. Siglos XVI-XVII, del que el volumen I, dedicado al siglo XVI, ya se ha 
al examinar los testimonios manuscritos inéditos en un trabajo anterior, el interés de los dos manuscritos que se conservan en la Biblioteca Nacional de París y la necesidad de una edición crítica que los contraste y emprenda un proceso de interpretación que coadyuve, si no a resolver, sí a añadir más matices, a la complejidad del corpus de Pedro de Navarra ${ }^{23}$.

Pero lo más importante, es que la Histoire générale de Languedoc se convertirá en la vía fundamental de transmisión de la que podría calificarse como la «leyenda negra» de Pedro de Navarra. El relato que se bosqueja de los años en los que ocupó el obispado de Cominges no habla muy en favor del escritor. La información que se nos da en esencia es la siguiente: poco antes de su regreso al Bearn francés, y como recompensa por su intervención en Roma ante Pío IV, se le otorgó la sede obispal de Cominges, vacante a causa de la muerte por homicidio de Carlos Carafa, el nepote del anterior papa $^{24}$. Fue convocado y asistió a la sesión final del Concilio de Trento, pero no permaneció allí hasta su conclusión. Se marchó de Trento en torno a septiembre de 1563, alegando como excusa, en una carta que dirigió a Catalina de Médicis, que no deseaba votar junto a los prelados franceses y la mayoría de los conciliares las medidas que querían tomar contra la jurisdicción real y la prelación del derecho de los monarcas sobre el poder temporal de los obispos. A su regreso, las relaciones con la reina de Navarra, Juana de Albret, comenzarían a tensarse, no tanto por razón de que ella fuera cabeza visible de los herejes y una apóstata del catolicismo romano, sino por motivos estrictamente económicos y personales, como las regalías que ella quería obligarle a pagar. Es muy posible que esto le llevara a ponerse al servicio de Felipe II, con el que mantuvo una estrecha correspondencia que « lui donnent l'air et l'apparence d'un espion» ${ }^{25}$. Se le acusó por ser sospechoso de servir de agente de Felipe II para convencer a Montluc e implicarlo en una operación destinada a conquistar para el monarca español la Guyena, tras una reunión secreta celebrada en Grenade-surGaronne en 1564. Fue denunciado formalmente de haber acuñado moneda falsa en su castillo de Alan, hecho por el que el Parlamento de Toulouse lo condenaría en $1565^{26}$.

publicado.

${ }^{23}$ Cf. G. Duruy, Le cardinal Carlo Carafa (1519-1561). Étude sur le pontificat de Paul IV, París, Hachette et $\mathrm{C}^{\mathrm{ie}}$, 1882., y particularmente, las páginas que le dedica J. Contrasty, Histoire des évêques de Comminges, Toulouse, Sistac, 1940.

24 A. de Ruble, anotaciones al volumen iv de Blaise de Montluc, Commentaires et lettres, I-V, ed. A. de Ruble, París, Société de l'Histoire de France, 1864-1872; ed. electrónica dividida en cinco unidades numeradas con el título Commentaires et lettres de Blaise de Montluc, maréchal de France, París, Société de l'histoire de France, 2002. Los Commentaires ocupan los vols. I-III (1864-1867) y las Lettres ocupan los vols. IV-V (1870-1872).. La alusión en el vol. v, p. 260.

25 Para todo ello remito al trabajo que precede a éste.

26 Cf. C. J. de Morales, «El poder de los secretarios reales: Francisco de Eraso», en J. Martínez Millán (dir.), La corte de Felipe II, Madrid, Alianza, 1998, pp. 107-148, y para lo que aquí interesa la «Carta autógrafa de Pedro de Navarra a Francisco de Eraso» (sin lugar ni data), incluida en el «Proceso del conde de 
Este panorama oscuro de los años en los que Pedro de Albret ocupó el obispado de Cominges puede ser corroborado documentalmente a través de diversas vías: desde la propia correspondencia de Pedro de Navarra, con informes anexos sobre la situación del caos religioso que se vivía en Francia, dirigidos a Felipe II a través de su Secretario de Estado, Francisco de Eraso $^{27}$; de la correspondencia que mantiene con la regente Catalina de Médicis; de las epístolas de Blaise de Montluc, y de la correspondencia mantenida por Antoine de Vendôme, rey de Navarra y marido de Juana de Albret, o por su primo, el cardenal Jorge de Armagnac, sin dejar de lado las anécdotas que se relatan en la correspondencia entre Carlos Borromeo y Viterbo, que encienden las alarmas sobre el comportamiento del nuevo obispo en la sede romana ${ }^{28}$. No deja de ser curioso el hecho de que, a pesar de que estos hechos puedan ser documentados, y de que esos testimonios obrasen en su poder, historiadores y estudiosos españoles como C. Gutiérrez ${ }^{29}$ o J. Goñi Gaztambide ${ }^{30}$, e incluso más recientemente, el mismo P. M. Cátedra ${ }^{31}$, hayan optado por pasar muy por encima de estas circunstancias, aludiendo a ellas, de la misma forma que las eludían, al tratarlas sólo como una especie de trasfondo que no resulta fiable del todo, omitiendo todo el peso de los documentos que atestiguan los hechos.

Afortunadamente, J. Goñi Gaztambide, ya con fecha de 1990, supo reparar estas carencias en el estudio que considero como definitivo para trazar, a día de hoy, la biografía del autor ${ }^{32}$. El pundonor de la historiografía literaria española, reacia a

Claramonte, senescal, gobernador de la ciudad de Tolosa, su tierra y jurisdicción, contra Remiro Ximénez de Oco, alcalde de los hijosdalgos de la ciudad de Estella, don Basilio de Labrit y demás opuestos a los bienes de don Pedro de Labrit, obispo de Comenges, sobre la paga de cinco mil noventa y un libras tornesas y demás derechos que los litigantes expusieron tener a los bienes de dicho obispo, hojas 1107, Secr. Miguel Barbo, 1578», Archivo General de Navarra, Pend. fajo 2, n. 10, fol. 726.

27 Correspondencia que puede consultarse en A. de Ruble, Antoine de Bourbon et Jeanne d'Albret, suite de «Le mariage de Jeanne d'Albret», I-IV, París, Adolphe Labitte, 1881-1886, y J. Šusta, Die Römische Curie und das Concil von Trient unter Pius IV. Actenstücke zur Geschichte des Concils von Trient, I-IV, Viena, Alfred Hölder, 1904-1914, en particular, para lo que aquí nos concierne, el volumen I.

28 C. Gutiérrez, Españoles en Trento, prólogo de J. Pérez Villanueva, Valladolid, CSIC, 1951, pp. 888-895. Este volumen es el I del Corpus Tridentinum Hispanicum.

29 J. Goñi Gaztambide, Los navarros en el Concilio de Trento y la reforma tridentina en la diócesis de Pamplona, Pamplona, Imprenta Diocesana (Pampinolensia. Publicaciones del Seminario Diocesano de Pamplona, Serie A, vol. II) 1947, pp. 99-132.

30 P. M. Cátedra, «Noticia de Pedro de Navarra» en su ed. de Pedro de Navarra, Diálogos de la differencia del hablar el escrevir, Bellaterra (Barcelona), «stelle dell'Orsa», 1985, pp. 11-57.

31 J. Goñi Gaztambide, «Pedro Labrit de Navarra, obispo de Comminges», Príncipe de Viana, 51 (1990), pp. 559-595.

32 De nuevo debo remitir a la nota 13 del trabajo previo a éste, y a la bibliografía de la que en ella doy cuenta, aunque sólo en las últimas décadas estas «disidencias» hayan cobrado valor de ley académica y hayan sido objeto de estudios con rigor científico, lejos de especulaciones novelescas y de intrigas palaciegas, a las que la realidad nos ha devuelto con ciertas sagas sobre el Siglo de Oro que, muy más que presumiblemente, se quedan en simple comedia de capa y espada si se atiende a las transgresiones en los terrenos de la crueldad y la moral que realmente acaecieron. Para este trabajo, con Pedro de Na- 
ahondar en laz zonas más sombrías de nuestros autores, casi siempre a la defensiva de lo que pueda considerarse como una conjura del hispanismo internacional contra el nacional, ha jugado muchas malas pasadas, y va en detrimento de un conocimiento integral de autores que no sólo ejercieron su papel de humanistas sino que también fueron protagonistas de hechos que cada vez resulta más infructuoso mantener al margen, aunque esas acciones vayan en detrimento de la idea de una España Imperial, sin claroscuros ${ }^{33}$.

Afortunadamente, en casos como los de Pedro de Navarra, que forma parte tanto del acervo histórico cultural hispánico como del francés, ese pundonor, pacato y moralizante, que se le atribuía desde una lectura parcial y fragmentada de su corpus, ha sido contrarrestado por las investigaciones exhaustivas que ya desde el siglo XVIII se comenzaron a realizar sobre una época crucial para la historia de Francia, la de los años en los que se sucedieron las guerras de religiones, y sobre los avatares del reino de Navarra, cuyo sucesor natural a la muerte de la hereje Juana de Albret, Enrique de Borbón, llegaría a convertirse en rey de Francia, bajo el nombre de Enrique IV, por su matrimonio con Marguerite de Valois, hija de Catalina de Médicis y de Enrique II. ${ }^{34}$

varra como foco de atención, simplemente me bastaría la transcripción de parte de su correspondencia, de la que se desprendería una imagen de las intrigas cortesanas que no coadyuvan a la mitificación de Carlos, el Emperador, en los términos en los que lo disecciona iconográficamente F. Checa Cremades, Carlos V y la imagen del héroe en el Renacimiento, Madrid, Taurus, 1987; ni a la forja de un retrato de Felipe II como adalid de un catolicismo militante desde el bastión de pureza y ascética que pudo representar El Escorial, tal como ciertas biografías canónicas, conjugando luces y sombras, han intentado trazar. Y ahí pueden coincidir desde G. Parker, Felipe II, Madrid, Alianza, 1991 hasta perspectivas más metódicas y despersonalizadas como las que presentan estudios más recientes (me basta citar como enfoques de aspectos parciales que desvelan la totalidad a N. Salomon, La vida rural castellana en tiempos de Felipe II, Barcelona, Ariel, 1982 o D. Goodman, Poder y penuria. Gobierno, tecnología y ciencia en la España de Felipe II, Madrid, Alianza, 1990). No hay que esperar, si seguimos los avatares cortesanos en las ciudades de Catilla que le tocaron vivir a Pedro de Navarra, ni en lugar ni en el tiempo, a esos bajos fondos que tan veladamente dejaría traslucir Luis Rosales, a cuentas de la decadencia de los Austrias y de las glorias del Imperio, en sus obras El sentimiento del desengaño en la poesía barroca y, sobre todo, en Pasión y muerte del Conde de Villamediana, hoy recopiladas en Obras Completas. III. Estudios sobre el Barroco, Madrid, Trotta, 1997. A Pedro de Navarra, ya en Toledo, ya en Valladolid, le cupo vivir una corte española que se asemeja tanto a esas «cuchilladas» como a las esperas inertes de las que da cuenta bajo el pathos del pretendiente Luis de Góngora en su epistolario (ed. de A. Carreira, Epistolario completo, Lausana, Sociedad Suiza de Estudios Helvéticos, 1999).

33 Cabe aquí, aunque sea una referencia excepcional y ajena a la bibliografía al uso, la cita del magnífico trabajo de reconstrucción historiográfica llevado a cabo por el director teatral y cinematrográfico francés, Patrice Chéreau, quien en su película La reine Margot (1994) da vida con tintes de épica y tragedia descarnadas los acontecimientos que rodearon al enlace del heredero de la dinastía navarra de los Borbones con la de los Valois, alcanzando una maestría sin par en su relato de la matanza de la noche de San Bartolomé, cuyas consecuencias serían decisivas para el futuro de las guerras entre las naciones europeas en una Europa perfectamente redimensionada desde perspectivas diversas por R. MacKenney, La Europa del siglo XVI. Expansión y conflicto, Madrid, Akal, 1996, J. H. Elliott, La Europa dividida. 1559-1598, Madrid, Siglo XXI, 19845 , J. R. Hale, Guerra y sociedad en la Europa del Renacimiento (1450-1620), Madrid, Ministerio de Defensa, 1990 y Q. Skinner, Los fundamentos del pensamiento político moderno. II. La Reforma, México, Fondo de Cultura Económica, 1993.

34 I. del Asso y del Río, Ignacio del, Ignatii de Asso. De libris quibusdam hispaniorum rarioribus disquisitio. 
A I. del Asso se debe la nota más completa sobre Pedro de Navarra y su obra hasta la fecha en la que la escribió, finales del siglo $\mathrm{XVIII}^{35}$, y he de reconocer que un siglo y medio más tarde aún seguía teniendo este carácter, obligando a los estudiosos, algunos en la categoría de develadores de su fuente y otros como francamente, en su omisión, sustentadores de una impostura que roza más que el plagio el hurto, a servirse de él como punto de referencia. Examinemos su contenido.

Tras las ya tópicas alusiones a su origen familiar, al episcopado de Cominges y a su asistencia al Concilio de Trento,

Ex splendidissima Albritorum familia, quae utriusque Navarrae imperium plures annos obtinuit, prognatus, Episcopus Commingensis in Gallia fuit, et a Consiliis Regis Christianissimi ${ }^{36}$

nos recuerda cómo sus diálogos son tan raros que incluso la diligencia de Nicolás Antonio los pasó por alto: «tantae raritatis sunt, ut Nicolai Antonii diligentiam effugerint». Puede comprobarse ya cómo la confusión que apuntaba en el apartado que dedicaba a Nicolás Antonio, provocada por las dos entradas que el erudito del XVII dedicaba a Pedro de Navarra como dos autores distintos, «D. Petrus de Navarra, alias de Labrit» $\mathrm{y}$ «Petrus Navarro», ya comenzaba a tener sus consecuencias ${ }^{37}$.

En Nicolás Antonio veíamos cómo el «ingenio», rasgo que, por inercia, siempre se atribuía a Pedro de Navarra, se aderezaba y desplazaba su acento hacia la enjundia de su «doctrina», en una convergencia de los vectores caracteriológicos procedentes de Yepes y d'Ohiénart. Aquí ese «desplazamiento» se consolida. Se nos concreta y se dota de una valencia prevalente a esta faceta, al dar relevancia al carácter «filosófico» de estos diálogos escritos en lengua española: «Dialogi Philosophici argumenti, quos Hispano eloquio conscripsit», aspecto que deberá ser tenido en cuenta dentro del trazado de la

Senatus Auctoritate. Cesaraugustae. Ex Typographia Mariani Miedis. Anno 1794, apdo. LIX «Petrus de Navarra».

35 Ibid., p. 35.

36 Cfr. G. Cabello Porras, «Pedro de Navarra. Semblanza de un humanista...», pp. 110-115.

37 Siempre teniendo en cuenta que esta acepción de «filosofía» debe atenerse a lo que A. Rallo Gruss, $L a$ prosa didáctica en el siglo XVI, Madrid, Taurus, 1987, pp. 59-60, delimitó como «márgenes de la filosofía» en la prosa de este periodo y que en absoluto deben diluirse en ese magma en el que todo vale que preside el proyecto editorial de J. L. Abellán, del que forma parte el volumen Historia crítica del pensamiento español. 2. La Edad de Oro (siglo XVI), Madrid, Espasa-Calpe, 1986. A. Rallo Gruss ha acotado con mayor precisión el territorio en el que debemos desenvolvernos desde esta perspectiva en su imprescindible Humanismo y Renacimiento en la literatura española, Madrid, Síntesis, 2007. 
figura del escritor como humanista al que vamos sumando rasgos que abundan en esa pluralidad de materias y opciones genéricas a las que ya me he referido. ${ }^{38}$

I. del Asso sitúa a Pedro de Navarra entre los escritores de filiación española, aunque nos dice que no puede afirmar con certeza que su nacimiento hubiera tenido lugar en España: «Huic itaque eo nomine inter Scriptores Hispanos locum concedimus, licet pro certo affirmare non sustineamus in Hispania natum fuisse», observación que me permite volver sobre esa singularidad que caracteriza a Pedro de Labrit, la de ser sujeto o materia de estudio tanto para la historiografía literaria francesa como para la española, lo que a su vez vale como excusa para que sea ignorado por una y por otra, como si no fuera materia de su incumbencia «nacional» y sí de la otra.

En el primer intento serio de descripción bibliográfica que conocemos, I. del Asso afirma haber visto y examinado dos ediciones de los diálogos de Pedro de Navarra con lugar, año y obras distintas. La primera a la que se refiere es la que encontró en la biblioteca de los dominicos de Zaragoza con el título Diálogos muy subtiles y notables con fecha de impresión en 1567 y publicados en la imprenta de Juan Millán. Señala que el volumen contiene cuarenta diálogos: los quince primeros titulados «Quál debe ser el chronista del príncipe», que «tratan del oficio del historiador y de aquéllos que describen las gestas de los príncipes». A éstos siguen cuatro diálogos sobre la vida rústica y la urbana, dedicados al marqués de Mondéjar, con el título «De la diferencia que hay de la vida rústica a la noble». Y, por último, treinta y un diálogos, «De la preparación de la muerte», dedicados al secretario de estado Juan de Eraso:

Duas horum Dialogorum editiones oculis usurpavimus, loco, anno, et opusculorum argumento diversas. Prima extat Caesaraugustae in Dominicanorum Bibliotheca, et sequenti titulo dignoscitur: Dialogos muy sutiles y notables hechos por el Ilustrisimo, y Reverendissimo Señor Don Pedro Navarra,Obispo de Comenga: ván dirigidos al muy Catholico Rey de España nuestro Señor. Impresos en Zaragoza por Juan Millan año 1567. 8. . Continentur in hoc volumine XL. Dialogi. Quinque priores hunc titulum habent: Qual debe ser el Chronista del Principe, nimirum de officio Historici, qui Principum res gestas describit. Hos excipiunt quatuor alii de vita rustica, et urbana ad Marchionem Mondejarensem supremi Senatus Praesidem: De la diferencia que hay de la vida rustica á la noble. Posteriores, qui XXXI. numero sunt: De la preparacion de la muerte, sive de exspectanda morte inscribuntur, quos Joanni de Eraso a secretis Status dedicavit. ${ }^{39}$

A continuación destaca uno de los puntos que serán fundamentales a la hora de estudiar la obra de Pedro de Navarra: su relación con las academias de la época. I. del Asso presta atención al hecho de que en la epístola dedicatoria a Francisco de

\footnotetext{
38 Ibid., pp. 35-36.

39 Juan de Eraso en I. del Asso.
} 
Eraso, ${ }^{40}$ Pedro de Navarra haga referencia, tras loar las virtudes de Hernán Cortés, a las sesiones académicas que se celebraban en su casa, enumerando a algunos de los participantes en dichas sesiones y proporcionando algunos apuntes sobre las materias que en estas reuniones se trataban, todas sobre temas graves y notables:

In Epistola nuncupatoria honorificam mentionem instituit de Ferdinando Cortesio Imperatoria virtute praeclaro, et optimarum artium studiis dedito, apud quem convenire solitos fuisse narrat viros omni doctrinae, et eruditionis laude cumulatos, qui aliud ex alio quaerentes locos gravissimos ex Philosophia tractabant. In his aderant Poggius Cardinalis, Joannes de Stunica, Antonius de Peralta, ejusque frater Bernardinus, Dominicus Pastorellus Archiepiscopus Calaritanus, Dominicus del Pico Aragonius, Joannes de Vega militari gloria conspicuus, aliique magni nominis viri. $^{41}$

Y es aquí donde se establece la relación genética entre lo que se trataba en dichas academias y unos doscientos diálogos que dice haber compuesto Pedro de Navarra a partir de dichas conversaciones. Así pues, todas las cosas que se discutían ordinariamente y con prudencia, estaban comprendidas en doscientos diálogos que él juzgó útil confiar a la memoria a través de la escritura, instrumento privilegiado para preservar del olvido esas disputas:

Igitur omnia fere quae ab illis prudenter disputabantur CC. Dialogis comprehensa memoriae mandare operae pretium esse judicavit. Sed cum haec opuscula admodum rara sint, ipsius auctoris verba hic apponere non ingratum lectoribus fore existimamus. ${ }^{42}$

Otra edición es la que vio en la biblioteca de los carmelitas. Es de Tolosa, sin año de impresión, y de ella afirma que contiene unos «Diálogos de la diferencia del hablar al escrebir» a los que siguen los «Diálogos de la inmortalidad del ánima», diálogos filosóficos en los que intenta refutar las herejías que se estaban extendiendo entre los aquitanos:

Altera editio, quam Caesaraugustae vidimus in Bibliotheca Carmelitani Coehobii; Tolosae prodiit sine ullo anni indicio: Dialogos de la diferencia del hablar al escribir (materia harto sutil e notable) dictados por el Ilustrisimo y Reverendisimo Señor Don Pedro de Navarra, Obispo IX de Cominge, y del Consejo del Rey Christianisimo dirigidos al Ilustrisimo Señor Don Luis de Beaumont, Condestable de Navarra, Conde de Lerin. A Tolosa en casa de Jacono Colomerio, Impresor de la Universidad $4 .^{\circ} \mathrm{Hi} \mathrm{V}$. priores Dialogi inscribuntur de loquendi scribendique diversa ratione ad Joannem Beaumontium Comitem Lerinensem. Sequuntur de inmortalitate animae argumentis ex Philosophia petitis demonstrata Dialogi IX. De la inmortalidad del anima segun vera, y natural Philosophia sin otra Escritura

\footnotetext{
$40 \quad$ Ibid., p. 86.

$41 \quad$ Ibid., p. 86.

42 Ibid., p. 86
} 
contra dirigidos al Beatisimo Papa Pio IV, de Casa de Medicis. In Epistola dedicatoria ad Pium IV. Pontificem maximum, opusculum hocce a se susceptum esse affirmat, ut refutaret illorum errores, qui opiniones absurdas adversus animae immortalitatem inter Aquitanos disseminaverant. ${ }^{43}$

Añade que en la epístola dedicatoria a Pío IV en los «Diálogos de la eternidad del ánima», Pedro de Navarra escribió que había compuesto doce diálogos sobre el origen, el desarrollo y los autores de las herejías que estaban asolando con miserias y aflicciones la provincia aquitana:

adjungitque scripsisse etiam Dialogos XII. in quibus ortum, progressum, et auctores Haeresium, quibus Aquitaniae Provincia per plures annos misere afflicta fuit, luculenter exposuit.

«Contra los quales (los Hereges) yo he escrito doce Dialogos, dirigidos á V. Beatitud, donde leerá todas las diversidades de heregías, y errores de los auctores, y defensores, que han sido, y son en este miserable Reyno». ${ }^{44}$

Estos dos últimos diálogos, los de la «Diferencia del hablar al escribir» y los «De la eternidad del alma», van unidos en esta edición que él vio a los tres que componían los Diálogos muy subtiles y notables. Por tanto, la obra de Pedro de Navarra quedaría ampliada así en «XVI» diálogos, según el texto de I. del Asso, aunque suponemos que es una errata por «XIV»:

Superioribus Dialogis subjiciuntur alii supra memorati de vita rustica, de officio Historici, et de expentada morte. Quare haec editio Caesaraugustana longe auctior est, cum Dialogos XVI. contineat, qui in illa desiderantur. ${ }^{45}$

La última parte de su artículo la dedica I. del Asso a dar cuenta de las epístolas que Pedro de Navarra escribió al duque de Villahermosa y de su procedencia y ubicación:

Praeter ea, quae modo recensuimus, nonnulla alia commentatum fuisse comparet ex litterit binis, quas ad Ducem Villaeformosae datas, et Apparatui ad Bibliotecam Scriptorum Aragoniae Joannis Francisci Andreae de Uztarroz insertas vidimus in Regia Bibliotheca Matritensi. ${ }^{46}$

Recoge las noticias que en ellas da Pedro de Navarra sobre las obras en las que se hallaba inmerso al final de su vida y que hasta hoy día se consideran perdidas:

\footnotetext{
43 Ibid., pp. 87-88.

$44 \quad$ Ibid., p. p. 88.

45 Ibid., p. 88.

46 Ibid., p. 88
} 
Trium foeminarum y las doce Noctes Sorianas, en las que se trataba, en las seis primeras, de toda la filosofía natural y del ser, y en las otras seis, de la diversidad de religiones:

In his ergo cujusdam opusculi Trium foeminarum titulo insigniti mentionem facit, et Noctes Sorianas XII. ab ipso concriptas allegat: quarum sex priores naturalis Philosophiae vias et rationem tradebant: sex aliae de Religionum diversitate tractabant. $^{47}$

Y, por último, presta atención a otro delos fragmentos delas cartas a Villahermosa, en el que Pedro de Navarra se preocupa por el diseño y la arquitectura de una casa, y su correspondencia con Felipe II a propósito de la propiedad y conveniencia de los materiales de construcción:

Refert etiam magnificam villam ad severioris Architecturae leges extructam, exquisitisque marmoribus ornatam aedificasse; ejusque exemplum ad Regem Catholicum misisse: Digo que yo he empleado algunas horas en hacer un disenio de otra, que embio al Rey Catholico, que olgára que V.S. la viera, porque tiene lo fuerte de los antiguos, lo muy curioso de los modernos, la perfecta Arquitectura de Vitruvio, \&c. et infra: S. M. prometió embiaria por los jaspes a mi Obispado, dó hay 14 especies, que les hacen poca ventaja los de Roma; et quando fuera servido de ellos, hicieran el octavo edificio de los siete del mundo.

Cum haec Epistola nullam anni notam adscriptam habeat, dubius haereo, an haec intelligi debeant de Escurialensi aedificio, quod Philippus II. marmoribus undique conquistis ornare voluerat. ${ }^{48}$

Transcurridos ya dos siglos desde que I. del Asso escribiera estas líneas, podríamos certificar que su introducción y clasificación de la obra de Pedro de Navarra sigue siendo más que válida y completa. Muy poco se ha añadido después, incluso en el plano editorial, ya que sólo una de sus series de diálogos ha contado con ediciones modernas $^{49}$. Y para el aspecto que nos interesa, el de completar el corpus de Pedro de

$47 \quad$ Ibid., p. 88

48 Ibid., pp. 88-89.

49 Nos referimos a las de los Diálogos de la diferencia del hablar al escrebir: Contamos con la edición diplomática de D. O. Chambers del ejemplar de la Biblioteca de la RAE, R-/78, [s.l., Berkeley?], [s.i.], 1968; con la edición ya citada de P. M. Cátedra, (1985), en la que no consta el ejemplar que se ha seguido para realizar la edición; y con la traducción al inglés de D. P. Seniff, que marca un hito en la revalorización e interés que despierta Pedro de Navarra en ámbitos académicos ajenos al territorio español: «About the Differences There are Between Speaking and Writing,» traducción al inglés de los Diálogos de la diferencia del hablar al escribir. Cf. D. P. Seniff, «Ong, ramism and Spain: The case of Pedro de Navarra's Dialogues on the Differences between Speaking and Writing», en Bruce E. Gronbeck, Thomas J. Farrell, Paul A. Soukup, eds., Media, conciousness, and culture: Explorations of Walter Ong's thought, Newbury Park, California, Sage Publications, 1991, pp. 121-132. Téngase en cuenta la nota: «I omit the introductory "Letter of dedication" [imprescindible para entender el diálogo] and a few repetitious passages, shown by ellipses, but otherwises adhere closely to the original Spanish» [lo que quiere significar, una masacre del texto original y un aviso para navegantes de la filología española del Siglo de Oro]. Vid., además de las introducciones de D. O. Chambers, P. M. Cátedra y D. P. Seniff a sus ediciones o traducción, el ensayo de E. L. Rivers, «Lo escrito y lo oral: don Pedro de Navarra», en L. Schwartz Lerner e I. Lerner, Homenaje a 
Navarra, aún siguen perdidas como decíamos el Trium foeminarum y Las cenas sorianas. Sólo puede añadirse como novedad el que los «doce diálogos sobre las herejías en Francia» corresponden al manuscrito, anónimo hasta ahora, de la Biblioteca del Monasterio de San Lorenzo de El Escorial al que ya nos hemos referido ${ }^{50}$.

De todos los aspectos que desarrolla I. del Asso hay uno que aquí nos interesa resaltar especialmente: la relación que existe entre las academias en las que Pedro de Navarra participó y la génesis de su propia obra. En el apartado que dedicaba a Nicolás Antonio ya anunciaba el significado profundo que conllevaba el escoger el diálogo como género literario para dar cauce a una expresión doctrinal. Como aduce L. Mulas, la forma dialógica no sólo conlleva la recuperación de un género largamente practicado en la antigüedad, sino que también responde al «esprit de controverse» del que estaba informada la cultura medieval. Remite la autora a

quell' abito mentale, cioè, che porta ad affrotare ogni problema (speculativo o dottrinario, teorico o pratico, concreto o astratto) attraverso una disputa, un confronto di opinioni; a verificare le proprie ipotesi controllandone la resistenza ad un assalto verbale ${ }^{51}$

cuyo ámbito más propicio sería el de las escuelas o el de las academias, de las que los diálogos serían una representación más o menos estilizada.

Así se establece un nexo de unión con la obra de Pedro de Navarra, desde la perspectiva del ámbito que genera el diálogo y que queda explicitado en sus dedicatorias y prólogos. Este ámbito sería el de las academias, y el diálogo funcionaría como transcripción de esas sesiones académicas ${ }^{52}$, tal como aparece en el párrafo de la epístola dedicatoria a Francisco de Eraso que I. del Asso ha seleccionado.

Ana María Barrenechea, Madrid, Castalia, 1984, pp. 307-311.

50 Cf. G. Cabello Porras, «Pedro de Navarra: revisión de un humanista...», pp. 76-77. Como paso previo a mi investigación doy cuenta de las memorias de licenciatura, defendidas, bajo mi dirección, en la Universidad de Málaga en julio de 1997 por Emiliano Gómez Ramos, Los «Diálogos de las herejías de Francia» (BMLE IV.b.30). Ensayo de integración en el corpus de diálogos de Pedro de Navarra»; y por María Isabel Iniesta Bonillo, Los «Diálogos de las herejías de Francia (BMLE. IV.b.30). Edición crítica y anotación. Debo hacer constar que la signatura del manuscrito, según los criterios actuales en la Biblioteca del Real Monasterio de San Lorenzo de El Escorial es la de «b-IV-30». Y deseo agradecer desde aquí la atención prestada y la disponibilidad del director de la citada Biblioteca, don José Luis del Valle, y la labor llevada a cabo por mi colaborador Jesús López Martínez.

51 L. Mulas, «La scrittura del dialogo. Teorie del dialogo tra cinque e seicento», en G. Cerina, C. Lavinio y L. Mulas, eds., Oralità e scrittura nel sistema letterario, Roma, Bulzoni, 1982, p. 257 [contamos con la traducción del texto en A. Rallo Gruss y R. Malpartida Tirado, eds., Estudios sobre el diálogo renacentista español. Antología de la crítica, Málaga, Universidad de Málaga, 2006, con el título de «La escritura del diálogo. Teorías del diálogo en los siglos XVI y XVII», pp. 85-105].

52 En un sentido análogo al que describe J. B. Avalle-Arce, «La estructura del Diálogo de la lengua», Dintorno de una ëpoca dorada, Madrid, Porrúa, 1978, pp. 57-72, o C. Barbolani, «Los diálogos de Juan de Valdés, ¿reflexión o improvisación?», en F. Ramos Ortega, coord., Doce consideraciones sobre el mundo his- 
Por otra parte, esas academias pueden funcionar como un ámbito interior al mismo diálogo. En ellas tiene lugar la lectura de otros diálogos, que adquieren así una función eminentemente didáctica. No olvidemos que Pedro de Navarra es un asistente asiduo a las academias ${ }^{53}$, allá donde se encontrase, como lo demuestra el hecho de que también participara activamente en la academia de Rodez presidida por su primo el cardenal Jorge de Armagnac, academia imbuida, como todas las francesas de aquel momento, de un espíritu diferenciado del que predominaba en las españolas. Nos referimos a la preocupación central: la regeneración religiosa, tema que podría estar vedado en las sesiones académicas contemporáneas a Felipe II en España. Recordemos con F. A. Yates:

\begin{abstract}
The idea of the «rebirth» of classicism is associated in Renaissance minds with notions of religious regeneration and rebirth which are mediaeval and Christian origin, and thus there is an intimate connection between the deep religious seriousness of Florentine Neo-Platonism and the outburst of intellectual and artistic activity which accompanied it. We shall find both the «encyclopaedic» pursuit of the arts and sciences and its religious background constantly present in the French academies. ${ }^{54}$
\end{abstract}

pano-italiano en tiempos de Alfonso y Juan de Valdés (Bolonia, abril de 1976), Roma, Publicaciones del Instituto Español de Lengua y Literatura de Roma / Anexos de Pliegos de Cordel, I, 1979, pp. 135-152 [recogido en A. Rallo Gruss y R. Malpartida Tirado, eds., Estudios sobr el diálogo renacentista español, pp. 315-336].

${ }^{53}$ Sobre su participación en las academias de Hernán Cortés, cf. W. A. Reynolds, Hernán Cortés en la literatura del Siglo de Oro, Madrid, Centro Iberoamericano de Cooperación. Editora Nacional, 1978, p. 200. W. F. King, Prosa novelística y academias literarias en el siglo XVII, Madrid, Anejo X del Boletín de la Real Academia Española, 1963, apunta que «la academia de Cortés quizá fuese la primera academia renacentista» en España, cita el pasaje de los Diálogos de la preparación de la muerte en el que Pedro de Navarra da cuenta de las reuniones y se refiere a la «incertidumbre existente con respecto al lugar de reunión de la academia» (pp. 22-24), coincidiendo en estas dudas con lo que ya había sostenido J. Sánchez en Academias literarias del Siglo de Oro español, Madrid, Gredos, 1961, p. 198: «El lugar de las reuniones de la Academia de Cortés también continúa siendo inseguro. Se cree que fue primero en Madrid y después en Sevilla, o más bien, en el cercano pueblo de Castilleja de la Cuesta, donde Cortés murió el 2 de diciembre de 1547. También pudo haber sido en Toledo, donde el Emperador pasaba largas temporadas. El Duque de Alba, don Fernando de Toledo, presidía las reuniones de esta academia, años después, en Toledo, cuando se congregaban en las casas del Marqués de Portalegre, don Juan de Silva y en época que las originales tertulias de Cortés, contaban más de treinta años de existencia. A la muerte de Cortés, las sesiones fueron dirigidas por su mujer, la Marquesa del Valle de Oaxaca». H. Keniston, en su estudio sobre el secretario de Carlos V, Francisco de los Cobos, trata sobre estas reuniones académicas, su organización y funcionamiento interno: Francisco de los Cobos, secretario de Carlos V, Madrid, Castalia, 1980, p. 343. J. Goñi, «Pedro Labrit de Navarra», p. 560, señala: «Durante varios años residió en Valladolid en la corte del emperador y frecuentó una academia literaria, que celebraba sus reuniones en la casa del célebre conquistador Hernán Cortés y a la que concurrían el nuncio Juan Poggio, Domingo Pastorello arzobispo de Cagliari, O. Min. Conv (1534-1547), el franciscano Domingo del Pico, el comendador mayor de Castilla Juan de Zúñiga, Juan de Vega, Antonio de Peralta marqués de Falces, Juan de Beaumont, Francisco de Cervantes Salazar y otros altos personajes de la aristocracia y del clero. En una de aquellas reuniones disertó sobre la preparación cristiana de la muerte, tema de actualidad que desarrolló en una de sus obras», añadiendo que «las reuniones se celebrarían entre 1540, fecha del regreso definitivo de Hernán Cortés a España y junio de 1546, en que don Pedro se encontraba en Roma».

54 F. A. Yates, The French Academies of the Sixteenth Century, Londres - Nueva York, Routledge, 1988, p. 4 
Si el «renacimiento» y la reforma religiosa eran ejes de discusión en las academias francesas, cuando los estudiosos intentan definir el tipo de conversaciones que se mantenían en la academia de Hernán Cortés coinciden en referirse a la «variedad y profundidad de éstas», a que los temas tratados en esta academia eran «origen de todo cuanto de bueno haya en su intelecto», ${ }^{55} \mathrm{O}$ a la calidad elevada de las discusiones sobre filosofía moral. ${ }^{56}$ Cualquier discusión en términos religiosos, tema central en algunos de los diálogos de Pedro de Navarra, supuestamente quedaba excluida, tanto desde la ortodoxia como desde la heterodoxia.

55 W. F. King, , op. cit., pp. 22-23

56 J. Sánchez, op. cit., p. 198. 